\title{
VIABILIDADE ECONÔMICA PARA PRODUÇÃO DE MEL EM PROPRIEDADE FAMILIAR ${ }^{1}$
}

\author{
Omar Jorge Sabbag ${ }^{2}$, Daniel Nicodemo ${ }^{2}$
}

\begin{abstract}
ECONOMIC VIABILITY

FOR HONEY PRODUCTION ON HOME FARM

In 2009, Brazil broke its own record for honey exports, generating revenues exceeding US\$ 65 million. However, there is a gap, concerning economic aspects, for most apiculturists inserted in that chain. Thus, the investment needed for honey production on a home farm in Cajuru, São Paulo State, Brazil, was estimated with investment and production costs based on the Total Operating Cost (TOC) used by the Instituto de Economia Agrícola, reaching R \$97,093.00 as the total investment amount. For the economic analysis, considering the orange blossom and wild honey production, the operating cost was $\mathrm{R} \$ 16,400.13$, whereas the cost for raw materials amounted to $70 \%$ of the Effective Operating Cost (EOC) and 26\% of the TOC, at a profit of $46 \%$. Whit respect to the equilibrium point, the apiculturist needs to produce $4,659 \mathrm{~kg}$ of honey, or sell it at the minimum price of $\mathrm{R} \$ 1.93 / \mathrm{kg}$, in order to cover production costs. It was possible to find out, based on cash flows, an IRR of $7.24 \%$ and that the initial investment returns in 10 years, showing attractive results for this farming segment, considering the reasonable use of production factors as well as a progressive increase in the amount produced.
\end{abstract}

KEY-WORDS: Apiculture; production costs; profitability.

\section{INTRODUÇÃO}

As pesquisas científicas aplicadas à apicultura brasileira, nas últimas décadas, têm sido numerosas e de grande qualidade, possibilitando o aumento da produtividade de nossas colmeias.

Em 2009, o Brasil gerou mais de US\$ 65 milhões com as exportações de mel (Sebrae 2010). O consumo per capita anual brasileiro de mel é muito pequeno (abaixo de $300 \mathrm{~g}$ ), principalmente quando comparado com o dos Estados Unidos e da Comunidade Europeia, que podem chegar a mais de

\section{RESUMO}

Em 2009, o Brasil quebrou o seu recorde de exportação de mel, gerando receita superior a US\$ 65 milhões. Entretanto, existe uma lacuna nos aspectos econômicos, para grande parte dos apicultores inseridos nesta cadeia. Desta forma, levantou-se o investimento necessário para a produção de mel, em uma propriedade familiar de Cajuru (SP), com estimativas de investimento e custos de produção baseados no Custo Operacional Total (COT) utilizado pelo Instituto de Economia Agrícola, obtendo-se R\$ 97.093,00 como valor total do investimento. Para a análise econômica, avaliando-se a produção de mel originária de flor de laranjeira e silvestre, o custo operacional total foi de $\mathrm{R} \$ 16.400,13$, considerandose que as despesas com insumos perfizeram $70 \%$ do Custo Operacional Efetivo (COE) e $26 \%$ do COT, obtendo-se índice de lucratividade de $46 \%$. Em relação ao ponto de nivelamento, o apicultor precisa produzir $4.659 \mathrm{~kg}$ de mel, ou vender ao preço mínimo de $\mathrm{R} \$ 1,93 / \mathrm{kg}$ a produção obtida, para cobrir os custos. Constatou-se, com base no fluxo de caixa, TIR de 7,24\% e que o investimento inicial retorna em 10 anos, mostrando resultados atrativos para este segmento agropecuário, considerando-se a racionalidade de uso dos fatores de produção, bem como um aumento progressivo na quantidade produzida.

PALAVRAS-CHAVE: Apicultura; custos de produção; rentabilidade.

$1 \mathrm{~kg} \mathrm{ano}^{-1}$. As razões fundamentais para este fato são o baixo nível de renda e a falta de hábito de consumo da população brasileira, decorrente do desconhecimento das propriedades do produto, além da falta de propaganda (Zandonadi \& Silva 2005).

A vasta biodiversidade da flora brasileira possibilita a obtenção de méis de diversas floradas, durante todos os meses do ano, com cores, aromas e sabores únicos. A apicultura está difundida em todas as regiões do Brasil, obtendo-se mel na Amazônia, Mata Atlântica, Pantanal, Caatinga, Pampa Gaúcho e Cerrado. Diferentemente da maioria das outras 
explorações agropecuárias, a apicultura gera pequeno impacto ambiental e favorece a manutenção dos ecossistemas, por causa da polinização (Imperatriz-Fonseca et al. 2006).

Há, no Brasil, várias espécies de abelhas nativas, além da exotica Apis mellifera. No Século XIX, as abelhas $A$. mellifera foram trazidas da Europa, pelos padres jesuítas, visando, principalmente, à produção de cera e mel. Em 1956, o pesquisador Warwick Estevam Kerr trouxe para o País a A. mellifera scutellata (abelha africana) que, ao acasalar-se com a Apis que aqui se encontrava, deu origem a um híbrido conhecido como abelha africanizada, com várias características importantes, destacando-se sua eficiência na polinização de diversas culturas, produção de mel e resistência a doenças (Couto \& Couto 2006).

A produção de mel no Brasil cresceu significativamente nas últimas décadas, atingindo 40.000 toneladas anuais, em 2003, posicionando o Brasil como o décimo primeiro no ranking mundial (Böhlke \& Palmeira 2006). O mercado brasileiro de produtos apícolas está avaliado, atualmente, em US\$ 360 milhões anuais, e pesquisas demonstram um potencial, a curto prazo, acima de US\$ 1 bilhão (Sebrae 2004).

A apicultura tornou-se instrumento de inclusão econômica e alternativa de emprego e renda. No Brasil, estima-se que 350 mil pessoas vivam com a renda da apicultura. Outra característica responsável pelo seu crescimento são as condições favoráveis à criação destes insetos encontradas em todas as regiões. Além disto, o apiário não necessita de cuidados diários, permitindo que os apicultores tenham outra fonte de renda. Entretanto, a atividade exige profissionalização, inclusive com o enfoque de que a ocupação na apicultura deve ser exercida como a atividade econômica principal do indivíduo, pois ainda é vista, por muitos, como atividade secundária e paralela às suas atividades profissionais (Böhle \& Palmeira 2006).

Neste contexto, existe uma lacuna nos resultados de pesquisas, no que se refere aos aspectos econômicos, pois grande parte dos apicultores necessita de suporte e orientação, quanto à estruturação, gestão, monitoramento e avaliação da atividade e comercialização de produtos apícolas.

Este trabalho possibilitou o destaque de alguns pontos de estrangulamento, permitindo que o apicultor possa concentrar seus esforços no gerenciamento da atividade, atingindo, assim, os seus objetivos de eficiência máxima em rentabilidade e melhor aproveitamento dos recursos produtivos existentes em seu negócio.

Para a manutenção de um agronegócio, é preciso que haja resultado econômico suficiente para cobrir todos os gastos efetuados, remunerar seu operador e gerar lucro suficiente para posterior reinvestimento na atividade, bem como na sua adaptação a mudanças, na realidade econômica.

Desta forma, o presente trabalho teve por objetivo analisar, economicamente, a criação da abelha melífera, em uma propriedade familiar localizada no município de Cajuru (SP). Especificamente, no processo de gestão desta atividade, procurou-se determinar os principais itens dos custos de produção, bem como caracterizar os parâmetros de rentabilidade em um ciclo produtivo, fatores essenciais para minimização de custos e aumento da lucratividade na produção de mel.

\section{MATERIAL E MÉTODOS}

Diante do objetivo de se avaliar os custos de produção e a rentabilidade no sistema de produção de mel, em uma propriedade familiar localizada no município de Cajuru (SP), esta pesquisa fez uso do levantamento de coeficientes técnicos, junto ao apicultor.

$\mathrm{O}$ apiário permanece na propriedade entre os meses de dezembro e julho, com obtenção de mel silvestre, a partir da exploração de 150 colmeias. Em junho e julho, a partir da coleta de enxames e divisão de famílias, 50 novos enxames são formados. De agosto a novembro, as colmeias são transportadas para uma propriedade de 100 ha, localizada no município de Cássia dos Coqueiros (SP), na qual se produz laranja. Neste local, as colmeias produzem mel a partir da coleta de néctar em flores de laranjeiras.

Para o desenvolvimento da análise de viabilidade da atividade, foi padronizado o cálculo de investimento para uma unidade de beneficiamento de mel, desde a sua instalação, o apiário e a casa do mel, em uma propriedade de 100 ha, correspondente à produção de $48 \mathrm{~kg} / \mathrm{ano} /$ colmeia ( $22 \mathrm{~kg}$ de mel silvestre e $26 \mathrm{~kg}$ de mel de flor de laranjeira), para 200 colmeias, totalizando uma produção de $8.500 \mathrm{~kg} /$ ciclo.

Vale destacar que o referido produtor familiar investiu em sua propriedade com recursos próprios, acrescidos do limite máximo permitido pelo progra- 
ma Pronaf destinado à apicultura, com juros de 8,75\% a.a., para o desenvolvimento da atividade.

Para o cálculo do custo de produção, foi utilizada a estrutura do custo operacional de produção utilizada pelo Instituto de Economia Agrícola (IEA), proposta por Matsunaga et al. (1976), a qual compõe-se de custo operacional efetivo (COE), com a utilização de mão-de-obra, máquinas/equipamentos, veículos e insumos, e o custo operacional total (COT), resultante do COE e acrescido das despesas com depreciação de máquinas e equipamentos, outras despesas ( $5 \%$ do COE) e encargos financeiros (juros de custeio, considerando-se $8,75 \%$ a.a.).

Nas operações referentes ao sistema de cultivo, foram computados os materiais consumidos e o tempo necessário de mão-de-obra para a realização de cada operação, definindo-se os respectivos coeficientes técnicos. Os preços médios foram coletados na região, em unidade de Real ( $\mathrm{R} \$$ ), e os dados de produção referem-se ao ciclo de 2010.

Os indicadores de lucratividade utilizados no trabalho foram os considerados por Martin (1997): receita bruta, que se constitui na produção pelo preço unitário médio pago aos produtores; receita líquida, referente à diferença entre a receita bruta e o custo total de produção; e índice de lucratividade, que se refere à proporção da receita bruta que se constitui em recursos disponíveis, em relação à receita líquida obtida. Ainda, reportou-se ao ponto de nivelamento da produção, caracterizado pela capacidade mínima de produção para cobertura dos custos totais de produção, bem como ao preço de equilíbrio, resultante do custo total de produção sobre a produtividade obtida.

Para a análise da viabilidade econômica do investimento, foi montado um fluxo de caixa, refletindo os valores das entradas e saídas dos recursos e produtos. A partir dos fluxos de caixa, foi determinada a Taxa Interna de Retorno (TIR) que, por definição, é aquela que torna o valor presente do fluxo líquido igual a zero e é calculada por meio da fórmula

$$
\sum \mathrm{t}_{\mathrm{t}=0}^{\mathrm{n}}(1+\rho)^{-\mathrm{t}}=0
$$

sendo que $\rho$ é a Taxa Interna de Retorno (TIR), $\mathrm{L}_{\mathrm{t}}$ os fluxos líquidos de caixa e t os períodos de produção da cultura, que variam de zero até n (Noronha 1981).

Ao se analisar um projeto pelo método acima, o critério adotado é de que sua taxa interna de retorno seja igual ou superior ao custo de oportunidade do capital para a empresa.
Outro indicador usado para analisar a viabilidade econômica da produção de mel foi o Período de Recuperação do Capital (Pay Back Period), que estabelece o tempo necessário para a recuperação do investimento.

\section{RESULTADOS E DISCUSSÃO}

O investimento total necessário para a produção de mel, em 200 colmeias completas, encontra-se detalhado na Tabela 1.

O sistema produtivo melífero, para a produção e posterior beneficiamento, compreende a existência de colmeias e todo o material de suporte para coleta de enxames, o apiário e a casa do mel (onde é realizada a retirada).

O valor total aproximado é de $\mathrm{R} \$ 97.093,00$, para o sistema de produção de mel, destacando-se as despesas com a casa do mel, que correspondem a 51\% do investimento inicial, considerando-se vida útil de 10 anos para os equipamentos depreciativos em destaque no sistema. Para o item instalação, as colmeias completas totalizaram $62,2 \%$, representando toda a estrutura necessária para a coleta de enxames. Já na casa do mel, a edificação consistiu em $80,8 \%$, representando o local, com todos os equipamentos necessários à coleta, como a centrífuga elétrica, peneiras e decantador, dentre outros.

Vale destacar que não foram considerados custos com máquinas de embalar, haja vista que o produtor fornece o mel direto aos entrepostos, para posterior envasamento e comercialização no mercado consumidor.

A Tabela 2 ilustra os coeficientes técnicos e o custo operacional total (COT) da produção de mel (200 colmeias), especificando as operações (horas de serviço) e os insumos utilizados no sistema (em quantidades especificadas).

Um fator relevante no item serviços refere-se ao custo de mão-de-obra com a revisão das colmeias ( $60 \%$ do custo com mão-de-obra e $18,08 \%$ do COE), devido ao fato de esta operação exigir uma frequência quinzenal de acompanhamento, por duas pessoas. Em relação às operações manuais no sistema de cultivo, os serviços representaram $30 \%$ do COE e $11,22 \%$ do COT.

Os materiais utilizados com maior intensidade no sistema de produção foram a cera bruta e o alimento energético, correspondendo, respectivamente, a $41 \%$ e $29 \%$ do COE, corroborando o fato de que a 
Tabela 1. Investimento necessário para a produção de mel (200 colmeias) (Cajuru, SP, 2010).

\begin{tabular}{|c|c|c|c|}
\hline Item & Quantidade & $\begin{array}{l}\text { Valor unitário } \\
\text { (R\$) }\end{array}$ & $\begin{array}{l}\text { Valor total } \\
\text { (R\$) }\end{array}$ \\
\hline \multicolumn{4}{|l|}{ Instalação* } \\
\hline Colmeia completa (fundo, tampa, ninho com quadros e melgueiras) & 200 & 120,00 & $24.000,00$ \\
\hline Núcleos para coleta de enxames & 20 & 47,00 & 940,00 \\
\hline Suporte de ferro & 200 & 15,00 & $3.000,00$ \\
\hline Faca & 2 & 12,00 & 24,00 \\
\hline Fitas/elásticos (coleta) & 370 & 0,20 & 74,00 \\
\hline Arame $\mathrm{n}^{\circ} 24(\mathrm{~kg})$ & 13 & 20,00 & 260,00 \\
\hline Caminhão F $4000^{1}$ & 1 & $10.000,00$ & $10.000,00$ \\
\hline Tela de transporte para núcleo & 20 & 14,00 & 280,00 \\
\hline Subtotal & & & $38.578,00$ \\
\hline \multicolumn{4}{|l|}{ Apiário* } \\
\hline Fumegador & 2 & 80,00 & 160,00 \\
\hline Macacão & 3 & 120,00 & 360,00 \\
\hline Botas & 3 & 30,00 & 90,00 \\
\hline Vassoura de quadros & 2 & 8,50 & 17,00 \\
\hline Luvas & 12 & 4,00 & 48,00 \\
\hline Alimentador Doolitle & 200 & 7,00 & $1.400,00$ \\
\hline Formão & 3 & 10,00 & 30,00 \\
\hline Tela de transporte para ninho & 200 & 16,50 & $3.300,00$ \\
\hline Tela excluidora de rainha & 200 & 18,00 & $3.600,00$ \\
\hline Subtotal & & & $9.005,00$ \\
\hline \multicolumn{4}{|l|}{ Casa do mel* } \\
\hline Edificação $\left(80 \mathrm{~m}^{2}\right)$ & 1 & $40.000,00$ & $40.000,00$ \\
\hline Mesa desoperculadora em aço inox & 1 & $1.900,00$ & $1.900,00$ \\
\hline Centrífuga elétrica em aço inox & 1 & $4.500,00$ & $4.500,00$ \\
\hline Peneira coadora em aço inox & 2 & 180,00 & 360,00 \\
\hline Decantador em aço inox (800 kg) & 1 & $1.700,00$ & $1.700,00$ \\
\hline Balde em aço inox & 2 & 150,00 & 300,00 \\
\hline Garfo desoperculador & 8 & 10,00 & 80,00 \\
\hline Derretedor de cera (30 L) & 1 & 250,00 & 250,00 \\
\hline Incrustador de cera & 1 & 70,00 & 70,00 \\
\hline Cilindro alveolar (cera manual) & 1 & 350,00 & 350,00 \\
\hline Subtotal & & & $49.510,00$ \\
\hline Total & & & $97.093,00$ \\
\hline
\end{tabular}

${ }^{1}$ Valor rateado para a atividade de apicultura, em função da utilização do veículo para outras finalidades de uso. * Itens depreciativos (considerou-se a vida útil dos equipamentos de 10 anos). Fonte: dados da pesquisa.

alimentação, na maior parte dos sistemas de produção, é um dos itens de maior dispêndio nos custos de produção. De maneira geral, os insumos contribuíram com $70 \%$ do COE e $26 \%$ do COT.

Destaca-se a depreciação linear, referindo-se ao valor depreciado dos equipamentos em destaque no sistema (Tabela 1) (valor inicial de $\mathrm{R} \$ 97.093,00$ e valor final reduzido em $10 \%$ ) sobre o tempo de vida útil dos mesmos, estimado em 10 anos. Ressalta-se que a depreciação correspondeu a 59\% do COT, representando a importância de se contabilizar os ativos (custos fixos da atividade). Segundo Majadas (2010), o que o produtor menos enxerga são os chamados custos fixos do negócio, como é o caso da depreciação. A não observância deste parâmetro compromete a sua atividade, tendo em vista que ele não terá mais capital para investir em um novo bem, que já está, supostamente, em estado de sucata, após seu período de vida útil.

Os demais itens agregados ao $\mathrm{COE}$ (outras despesas e encargos financeiros) são destacados para explicitar os valores obtidos para o COT. Neste sentido, o COT foi de R \$16.400,13, sendo composto por $\mathrm{R} \$ 1.840,33$ com serviços e $\mathrm{R} \$ 4.277,00$ com insumos, além de R $\$ 9.709,30$ com depreciação de máquinas e equipamentos, $R \$ 267,63$ com juros de custeio e R $\$ 305,87$ com outras despesas.

Verificou-se que a receita bruta foi de $\mathrm{R} \$ 30.376,00$ (Tabela 3), relacionada, diretamente, à produtividade obtida $(8.500 \mathrm{~kg} / \mathrm{ano})$, em relação 
Tabela 2. Coeficientes técnicos e custo operacional total (COT) para a produção anual de mel (200 colmeias) (Cajuru, SP, 2010).

\begin{tabular}{|c|c|c|c|c|c|}
\hline Descrição & Especificação & Valor unitário & Quantidade & $\begin{array}{l}\text { Total } \\
\text { (R\$) }\end{array}$ & $\begin{array}{c}\text { Total } \\
\text { (US\$)* }\end{array}$ \\
\hline \multicolumn{6}{|l|}{ Serviços } \\
\hline Troca de cera & $\mathrm{HH}$ & 3,95 & 8 & 31,59 & 17.17 \\
\hline Limpeza da área & $\mathrm{HH}$ & 3,95 & 8 & 31,59 & 17.17 \\
\hline Revisão das colmeias & $\mathrm{HH}$ & 3,95 & 280 & $1.105,78$ & 600.97 \\
\hline Retirada do mel & $\mathrm{HH}$ & 3,95 & 72 & 284,34 & 154.53 \\
\hline Transporte das colmeias & $\mathrm{HH}$ & 3,95 & 2 & 7,90 & 4.29 \\
\hline Beneficiamento & $\mathrm{HH}$ & 3,95 & 96 & 379,12 & 206.05 \\
\hline Subtotal & & & & $1.840,33$ & $1,000.18$ \\
\hline \multicolumn{6}{|l|}{$\overline{\text { Insumos }}$} \\
\hline Alimento energético & $\mathrm{kg}$ & 1,50 & 800 & $1.200,00$ & 652.17 \\
\hline Ração protéica & $\mathrm{kg}$ & 1,60 & 160 & 256,00 & 139.13 \\
\hline Cera bruta & $\mathrm{kg}$ & 25,00 & 70 & $1.750,00$ & 951.09 \\
\hline Aquisição de rainhas & Unidade & 15,00 & 30 & 450,00 & 244.57 \\
\hline Combustível (reparos/lubrificantes) & 1 & 3,00 & 207 & 621,00 & 337.50 \\
\hline Subtotal & & & & $4.277,00$ & $2,324.46$ \\
\hline Custo operacional efetivo (COE) & & & & $6.117,33$ & $3,324.63$ \\
\hline Outras despesas (5\% do COE) & & & & 305,87 & 166.23 \\
\hline Depreciação & & & & $9.709,30$ & $5,275.79$ \\
\hline Juros de custeio & & & & 267,63 & 145.45 \\
\hline Custo operacional total (COT) & & & & $16.400,13$ & $8,913.11$ \\
\hline
\end{tabular}

* US\$1.00 $=$ R $\$ 1,84$. Fonte: dados da pesquisa.

ao preço alcançado pelo apicultor $(\mathrm{R} \$ 3,28 / \mathrm{kg}$ para o mel silvestre e $\mathrm{R} \$ 3,76 / \mathrm{kg}$ para o mel de laranjeira), na venda direta ao entreposto.

O lucro operacional (LO), obtido pela diferença entre a receita bruta e os custos totais, foi de R\$ 13.975,87. O índice de lucratividade (IL), que indica a proporção da receita bruta que se constitui em lucro após a cobertura dos custos, resultou em $46,01 \%$, evidenciando que o sistema de produção de mel, em propriedade familiar, é rentável. Conforme Silva \& Machado (2001 apud Oliveira et al. 2004), vale destacar que a lucratividade obtida mostra-se superior, em relação a outros sistemas de exploração como o milho $(21,81 \%)$ e pecuária bovina $(11,07 \%)$.

Da mesma forma, para equilibrar os custos totais de produção, o apicultor precisa produzir, no mínimo, $4.659 \mathrm{~kg} /$ ciclo, a partir de 200 colmeias, na fase inicial, assim como vender ao preço médio mínimo de $\mathrm{R} \$ 1,93 / \mathrm{kg}$, para cobrir os custos totais de produção. Estes dados indicam que o apicultor obteve produção $82,4 \%$ superior à de equilíbrio (considerando-se os valores pagos $/ \mathrm{kg}$ ), podendo-se inferir que o apicultor em questão trabalhou de forma eficiente e racional os fatores de produção da sua propriedade.
Para a análise de investimento, durante os ciclos anuais de produção, observaram-se resultados positivos para a produção (Tabela 4), haja vista que o VPL é positivo (considerado a partir do $10^{\circ}$ ano de produção), com TIR de 9,61\% para o retorno do capital investido em, aproximadamente, 12 anos de produção melífera. Para a relação benefício/custo (IBC), verifica-se que há retorno de $73 \%$ para o apicultor em sua atividade (o IBC é um indicador

Tabela 3. Rentabilidade da produção anual de mel (200 colmeias) (Cajuru, SP, 2010).

\begin{tabular}{|c|c|}
\hline Item & 200 colmeias (ciclo anual) \\
\hline Produção (kg) & 8.500 \\
\hline Preço $(\mathrm{kg})$ & $3,28^{*}$ e $3,76^{* *}$ \\
\hline Receita bruta (R\$) & $30.376,00$ \\
\hline Custo total (R\$) & $16.400,13$ \\
\hline Lucro operacional (R\$) & $13.975,87$ \\
\hline Índice de lucratividade (\%) & 46,01 \\
\hline Produção de equilíbrio ${ }^{1}(\mathrm{~kg})$ & 4.659 \\
\hline Preço médio de custo ${ }^{2}(\mathrm{R} \$)$ & 1,93 \\
\hline
\end{tabular}


relativo, que mede a expectativa de retorno para cada unidade de capital imobilizada no projeto). Conforme aponta Nogueira (2007), na análise da TIR, observa-se a viabilidade econômica do projeto, haja vista que a mesma foi superior à Taxa Mínima de Atratividade (TMA), que, neste caso, foi de $6 \%$ a.a.

Segundo Kreuz et al. (2008), enquanto a TMA permanecer inferior à TIR, as expectativas são de que haja mais ganho em investir-se no projeto do que deixar o dinheiro aplicado à TMA. Desta forma, neste trabalho, é compreensível a segurança da decisão de se empreender na apicultura, pois seria necessário que a TMA (estimada em $6 \%$ a.a.) alcançasse o valor da TIR (9,61\% a.a.), para que o mercado financeiro propiciasse o mesmo retorno do agronegócio do mel.

Vale destacar que a TIR apresentada mostrou-se superior, comparativamente a outros trabalhos do segmento agropecuário, analisados com um horizonte de mesmo período, como a pecuária extensiva (3,07\% - inviável), podendo aumentar para $11,01 \%$, por meio da diversificação com o eucalipto (Hudson \& Garcia 2009).

Matsushita. et al. (2010) também apontam TIR de $6,1 \%$ (média de 4 anos), para as culturas de milho e soja existentes, para agricultores familiares no município de Palmeira (PR), apontando melhorias para incrementar o retorno do investimento, com a diversificação de culturas como o eucalipto.

Quanto maior o período de tempo para se recuperar o capital investido, maior o risco do projeto. Neste caso específico para a apicultura, é plausível que o pay back seja moderadamente alto, devido ao período de maior amortização dos investimentos iniciais na propriedade.

Este trabalho oferece um parâmetro de custo para o apicultor, podendo, de certa forma, contribuir para um melhor planejamento de atividades, de maneira que, apesar dos altos investimentos iniciais, possivelmente poderá reduzir seus custos com o manejo racional no sistema produtivo, o que seria mais atrativo para o mercado setorial (menor pay back e maior TIR), tornando mais viável as suas atividades de produção e comercialização de mel.

\section{CONSIDERAÇÕES FINAIS}

A exploração da abelha melífera é considerada uma atividade que possui facilidade de execução, com grandes possibilidades de comercialização.

Como itens direcionadores dos custos variáveis no custo operacional efetivo, a cera bruta e o alimento energético corresponderam, respectivamente, a $41 \%$ e $29 \%$ do COE. Desta forma, na propriedade

Tabela 4. Fluxo de caixa, Valor Presente Líquido, TIR, B/C e Pay Back Period para a produção anual de mel (200 colmeias) (Cajuru, SP, 2010).

\begin{tabular}{|c|c|c|c|c|}
\hline \multirow{2}{*}{ Itens } & \multicolumn{4}{|c|}{ Anos } \\
\hline & 0 & 5 & 10 & 12 \\
\hline \multicolumn{5}{|l|}{ Saídas } \\
\hline \multicolumn{5}{|l|}{1 - Investimento } \\
\hline Instalação & $38.578,00$ & & & \\
\hline Apiário & $9.005,00$ & & & \\
\hline Casa do mel & $49.510,00$ & & & \\
\hline Subtotal & $-97.093,00$ & & & \\
\hline \multicolumn{5}{|l|}{2 - Custo operacional } \\
\hline Produção de mel & & $16.400,13$ & $16.400,13$ & $16.400,13$ \\
\hline 3 - Total & $-97.093,00$ & $16.400,13$ & $16.400,13$ & $16.400,13$ \\
\hline 4 - Receita bruta & & $30.376,00$ & $30.376,00$ & $30.376,00$ \\
\hline 5 - Fluxo líquido anual & $-97.093,00$ & $13.975,87$ & $13.975,87$ & $13.975,87$ \\
\hline 6 - Fluxo líquido acumulado & & $-27.213,63$ & $42.665,73$ & $70.617,48$ \\
\hline VPL & & $-38.221,54$ & $5.770,64$ & $20.078,54$ \\
\hline TIR & & $-10,05 \%$ & $7,24 \%$ & $9,61 \%$ \\
\hline \multicolumn{5}{|l|}{ Pay Back Period } \\
\hline $\mathrm{B} / \mathrm{C}$ & $97.093,00$ & 0,72 & 1,44 & 1,73 \\
\hline
\end{tabular}


familiar, tem-se custo total de $\mathrm{R} \$ 16.400,13$, para produzir mel em 200 colmeias/ano. Na análise da rentabilidade, observou-se índice de lucratividade de 46,01\% (mais representativo, em comparação a outros sistemas de exploração agrícola), bem como produção final de $8.500 \mathrm{~kg} / \mathrm{ano}$, representando margem superior de $82,4 \%$, em relação à produção de equilíbrio.

Com base nos resultados apresentados, pode-se concluir que a propriedade produtora de mel em Cajuru (SP), embora apresente TIR de 7,24\%, torna-se viável, pelo fato de esta ser maior do que a TMA, podendo elevar-se a 9,61\%, para 12 anos de produção. Entretanto, uma das alternativas para se melhorar o desempenho técnico e econômico seria a racionalização dos fatores de produção, bem como a diversificação das explorações existentes.

Em síntese, a quantificação de todos os insumos e serviços de um apiário inseridos em uma planilha de custos é uma das ferramentas informacionais e, portanto, de competitividade no setor. Através de uma correta avaliação do comportamento dos preços de mercado e do potencial de comercialização, permite-se gerenciar, de forma otimizada, o empreendimento.

\section{REFERÊNCIAS}

BÖHLKE, P. B.; PALMEIRA, E. M. Inserção competitiva do pequeno produtor de mel no mercado internacional. 2006. Disponível em: <http://www.eumed.net/cursecon/ ecolat/br/06/pbb.htm>. Acesso em: 10 jun. 2010.

BORNIA, A. C. Análise gerencial de custos. São Paulo: Bookman, 2002.

COUTO, R. H. N.; COUTO, L. A. Apicultura: manejo e produtos. 3. ed. Jaboticabal: Funep, 2006.

GAMEIRO A. H.; CARDOSO C. E. L. Custos na piscicultura. 2001. Disponível em: $<$ http://cepea.esalq. usp.br/zip/Analise custo.pdf>. Acesso em: 28 nov. 2007.

HUDSON, L. S.; GARCIA, M. A. Sistema agrossilvipastoril: uma opção de rentabilidade e sustentabilidade. 2009. Disponível em $<$ http://www.ilpf. com.br/artigos/Viabilidade\%20ilpf.pdf $>$. Acesso em: 24 nov. 2010.

IMPERATRIZ-FONSECA, V. L.; SARAIVA, A. M.; DeJONG, D. Bees as pollinators in Brazil: assessing the status and suggesting best practices. Ribeirão Preto: Holos, 2006.

KREUZ, C. L; SOUZA, A.; CLEMENTE, A. Custos de produção, expectativas de retorno e de riscos do agronegócio mel no planalto norte de Santa Catarina. Custos e @gronegócio on line, Recife, v. 4, n. 1, jan./abr. 2008. Disponível em: $<\mathrm{http}: / / \mathrm{www} . c u s t o s e a g r o n e g o c i o o n l i n e$. com.br/numero1v4/mel.pdf > . Acesso em: 24 nov. 2010.

LAPPONI, J. C. Projetos de investimento: construção e avaliação do fluxo de caixa - modelos em Excel. São Paulo: Lapponi, 2000.

LEONE, G. S. G. Curso de contabilidade de custos. São Paulo: Atlas, 2000.

LOPES, M. A.; CARVALHO, F. M. Custo de produção de gado de corte: uma ferramenta de suporte ao pecuarista. In: JORNADA TÉCNICA EM SISTEMAS DE PRODUÇÃO DE BOVINOS DE CORTE E CADEIA PRODUTIVA: TECNOLOGIA, GESTÃO E MERCADO, 1., Porto Alegre, 2006. Anais... Porto Alegre: UFRGS/DZ/ NESPRO, 2006. 1 CD-ROM.

MAJADAS, B. Faça de sua propriedade um negócio rentável. Revista Produz, Goiânia, n. 48, p. 56-61, 2010.

MARTIN, N. B. et al. Sistema "CUSTAGRI": sistema integrado de custos agropecuários. São Paulo: IEA/SAA, 1997.

MATSUNAGA, M. et al. Metodologia de custo utilizada pelo IEA. Agricultura em São Paulo, São Paulo, v. 23, n. 1, p. 123-139, 1976.

MATSUSHITA, M. S. et al. Proposta de melhoria das propriedades familiares a partir da introdução de cultivos florestais. Revista Acadêmica Ciências Agrárias e Ambientais, Curitiba, v. 8, n. 2, p. 251-260, abr./jun. 2010.

NOGUEIRA, E. Análise de investimentos. In: BATALHA, M. O. (Coord). Gestão agroindustrial. São Paulo: Atlas, 2007. p. 223-224.

NORONHA, J. F. Projetos agropecuários: administração financeira, orçamentação e avaliação econômica. São Paulo: Fundação Estudos Agrários Luiz de Queiroz, 1981.

OLIVEIRA, F. et al. Produção de mel na região noroeste do Estado de São Paulo: um estudo de caso de produtor familiar. Informações Econômicas, São Paulo, v. 34, n. 2, p. 15-24, fev. 2004.

REIS, R. P. Introdução à teoria econômica. Lavras: UFLa/ Faepe, 1999.

SABBAG, O. J. et al. Análise econômica da produção de tilápias (Oreochromis niloticus) em um modelo de propriedade associativista em Ilha Solteira/SP. Custos e @gronegócio on line, Recife, v. 3, n. 2, jul./dez. 2007. Disponível em: <http://www.custoseagronegocioonline. com.br/numero2v3/analise\%20economica.pdf $>$. Acesso em: 10 mar. 2010

SERVIÇO BRASILEIRO DE APOIO ÀS MICRO E PEQUENAS EMPRESAS (Sebrae). Exportação de mel 
em 2009 bate recorde. 2010. Disponível em: <http://www. sebrae.com.br/setor/apicultura/sobre-apicultura/mercado/ historico-de-exportacoes>. Acesso em: 01 jul. 2010.

SERVIÇO BRASILEIRO DE APOIO ÀS MICRO E PEQUENAS EMPRESAS (Sebrae). Programa de desenvolvimento da apicultura no Rio Grande do Norte - RN. 2004. Disponível em: <http://www.sebraern.com. $b r>$. Acesso em: 24 nov. 2010.

SOUZA, A.; CLEMENTE, A. Decisões financeiras $e$ análise de investimentos. 5. ed. São Paulo: Atlas, 2004.
ZANDONADI, D. A.; SILVA, O. M. Análise da competitividade do Brasil no mercado internacional de mel. In: CONGRESSO DA SOBER, 43., Ribeirão Preto, 2005. Anais... Ribeirão Preto: FEA/USP, 2005. 1 CDROM.

ZDANOWICZ, J. E. Fluxo de caixa: uma decisão de planejamento e controle financeiro. Porto Alegre: Sandra Luzzata, 1998. 